TREE-RING RESEARCH, Vol. 61(2), 2005, pp. 73-76

\title{
RESEARCH REPORT SOME GEOMETRIC CONSTRAINTS ON RING-WIDTH TREND
}

\author{
RICHARD L. PHIPPS ${ }^{1}$ (RET.) \\ U.S. Geological Survey
}

Reston, VA 22101

\begin{abstract}
Simulations of tree rings from trees of undisturbed forest sites are used to describe natural, longterm width trends. Ring-width trends of canopy-sized white oak are simulated from regressions of $B A I$ (ring area) data of real trees. Examples are given of a tree from a typical re-growth forest in Illinois and of a more slowly growing tree from an old-growth forest in Kentucky. The long-term width trend was simulated as being toward constant ring width regardless of growth rate of the tree. Conditions by which either increasing or decreasing ring-width trends could be simulated from the same linear BAI trend are examined. I conclude that curvilinear width trends, either increasing or decreasing, represent width adjustments to changes in growth rate (BAI trend) after which the width trend stabilizes to a near-constant value. Interpretation of ring-width trends of trees from undisturbed stands may be useful in assessing stand disturbance history.
\end{abstract}

Keywords: Ring-width, growth trend, simulation, BAI, Quercus alba, White oak.

\section{INTRODUCTION}

When ring area (basal area increment, $B A I$ ) remains constant from year to year, ring-width decreases as diameter increases. However, $B A I$, for years after a tree reaches canopy size, typically increases each year (Phipps and Whiton 1988). In undisturbed stands, $B A I$ trends of deciduous species approximate straight lines with a positive slope for years after a tree has attained canopy status, which can be described by linear regression (Phipps and Whiton 1988). Intuitively, if increase in $B A I$ were great enough, $B A I$ could keep pace with the increase in diameter, and ring width would remain constant or even increase. Thus, it might seem that faster growing trees (greater $B A I$ slope) would show long-term ring-width trends that more nearly result in constant width than would slower growing trees. Contrary to this bit of speculation, the long-term ring-width trend appears to be toward constant ring width, whether growth rate is slow or fast.

${ }^{1}$ Present address: 4204 Woodland Dr., Fairfax, VA 22030; rlphipps348@AOL.com
The purpose of this report is to illustrate examples of long-term ring-width trend unencumbered by year-to-year variations cause by climate. With the climatic component removed, width trends can be described as geometric progressions. This can be illustrated by simulating long-term ring-width trends. Because $B A I$ trends tend to be near linear, the inherent difficulties in defining and simulating curvilinear trends may be somewhat averted by simulating the width trends from the $B A I$ trends. $B A I$ at year $t$ may be derived by converting ring width, $w_{p}$, to radius length, $r$, and calculating area:

$$
r_{t}=r_{t-1}+w_{t}
$$

and

$$
B A I_{t}=\pi\left(r_{t}^{2}-r_{t-1}^{2}\right.
$$

$B A I$ trend of a real tree, described in terms of linear regression of the trend, can be projected forward and backward in time and used to calculate the ring-width series that would have been required to produce the $B A I$ trend. This is illustrated below with data of a white oak (Quercus alba) from a secondary forest at Allerton Park in central 


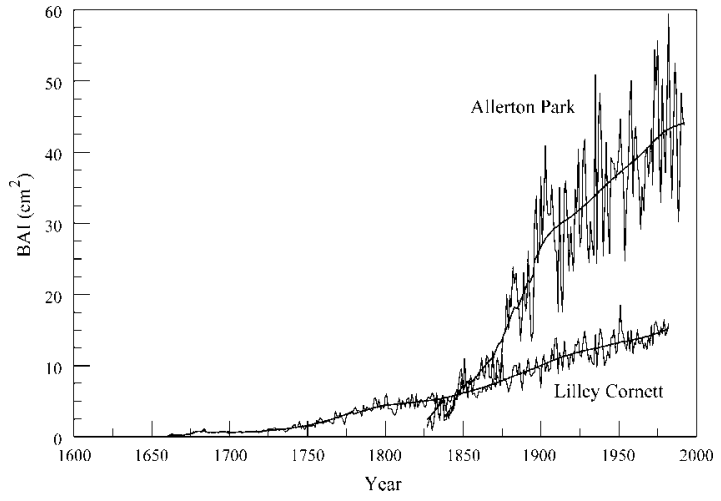

Figure 1. $B A I$ trend of two white oak collections. The fastergrowing trees are from Allerton Park, IL, and the slower-growing trees are from the Lilly Cornett collection in eastern KY. BAI data were calculated for each core and then averaged to produce the collection means shown. The means were smoothed with a 60-year cubic spline. The Lilley Cornett collection contains 40 cores and the Allerton collection contain 23 cores.

Illinois and with data of a more slowly growing white oak from the Lilley Cornett forest in eastern Kentucky. To avoid complexities associated with understory trees, analysis was restricted to rings formed while the tree crown was in the forest canopy.

\section{ALLERTON PARK WHITE OAK}

Tree AWO-1 was selected to be representative of our Allerton Park increment core collection because its $B A I$ trend is similar to that of the mean collection for the years that it was in the forest canopy (Figure 1). Having found that white oak typically attains canopy status at about the time that the inside bark diameter at breast height $(d b h)$ reaches $20 \mathrm{~cm}$ (Phipps and Whiton 1988), a 10$\mathrm{cm}$ radius length was used in determining that AWO-1 reached canopy size around 1900. BAI values were calculated from the regression equation of BAI for years that AWO-1 was in the canopy, 1900-1992 (Figure 2). The regression equation was then used to project $B A I$ backwards to 1851 , the year from the regression in which radius length $=0$, and forward to the year 2200. Just as it is necessary to use radius length $(r)$ in order to calculate $B A I$, so too is it necessary to include ra-

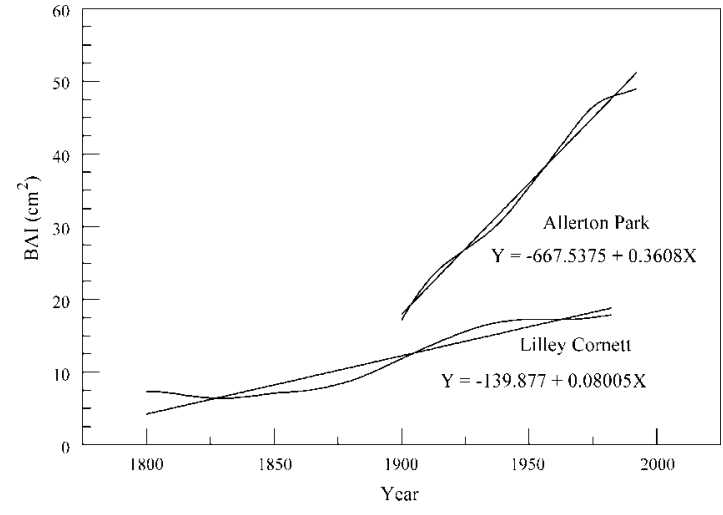

Figure 2. Smoothed $B A I$ trends and regressions for two white oak samples. Shown are years that radius $\geq 10 \mathrm{~cm}(1900$ 1992 for Allerton Park white oak, AWO-1, and 1800-1982 for Lilley Cornett white oak, 103241).

dius length in order to calculate width $(w)$ from $B A I$.

Three ring-width simulations (Figure 3) were performed that were all based on the same $B A I$ trend, but each was set to a different radius length for $1900(10,12$ and $14 \mathrm{~cm})$. The first ring-width simulation was based on the actual radius in 1900 of $10 \mathrm{~cm}$, and so for the years of real data (19001992) approximates a smooth curve of actual ring width. This simulation shows a trend of decreasing ring width that tails out to a steady state (nearly constant width) in one to two hundred years (Figure 3). Summing the simulated ring widths for-

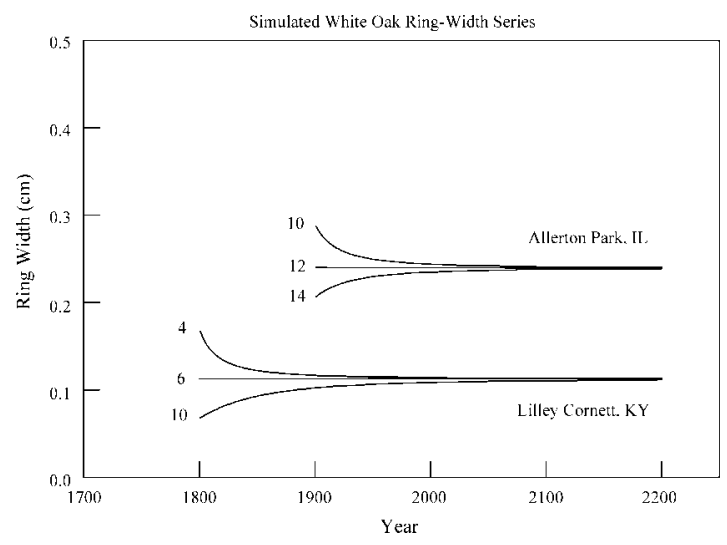

Figure 3. Three ring-width simulations, each, for Allerton Park white oak (sample AWO-1) and Lilley Cornett white oak (sample 103241). Number preceding each curve is starting radius length $(\mathrm{cm})$ for that simulation. 
ward from 1851 (when $B A I$ regression value $=0$ ) indicated a radius length of $12 \mathrm{~cm}$ by 1900 . A 12$\mathrm{cm}$ radius in 1900 was used as the starting point for the second ring-width simulation. This second simulation shows an essentially constant ring width forward from 1900 (Figure 3), and represents the ring widths that would have occurred if growth followed the same $B A I$ trend (slope) before reaching the canopy. The third scenario was based on a radius length in $1900(14 \mathrm{~cm})$ that could have occurred if accumulative growth prior to 1900 was greater than that simulated by the linear trend of the canopy BAI. Because growth was on a longer radius, and $B A I$ was designated as being the same, ring width was necessarily smaller in 1900. By the year 2200 , ring width was essentially coincident with that of the first two simulations (Figure 3).

If the $B A I$ trend of the understory tree had been the same as after the tree reached canopy size, the tree would have dated back to 1851. Sample AWO-1 came very close to the center of the tree and the centermost measured ring was 1874 . This would suggest that the actual tree (at sample height) may not predate 1870 , and grew at a greater rate as an understory tree than it did after reaching the canopy around 1900 .

The slope of the pre-1900 BAI trend of the real tree (AWO-1) was greater than that after 1900, also meaning that growth was increasing at a greater rate before 1900 than after. It might be speculated that AWO-1 was established in a relatively open forest area allowing for a rapidly increasing crown size as the young tree grew from small tree to sub-canopy to canopy level. Then, after the canopy closed, the slope of the BAI trend would have decreased as a result of increasing competition from surrounding trees. It appears that canopy closure of the trees around AWO-1 and attainment of canopy size $(10-\mathrm{cm}$ radius) by AWO-1 must have occurred at about the same time.

The mean collection BAI trend (Figure 1), which also shows a greater slope before 1900 than after, suggests that the entire site, not just those trees around tree AWO-1, was relatively open when the collection trees were small, understory trees in the early 1800 's. Removing only a part of the overstory would have been sufficient to allow rapid growth rates shown for the Allerton Park collection prior to the canopy again closing around 1900 (Figure 1).

\section{LILLEY CORNETT WHITE OAK}

The BAI trend of tree 103241 was selected as representative of the Lilley Cornett collection. The Lilley Cornett data are from a collection made by Dr. Ed Cook (data available through the ITRDB) from a site in eastern Kentucky. Diameter data were not available for this collection, but were inferred from the increase in the amplitude of the yearly variations in $B A I$ that I have observed to be associated with release of an understory tree into the canopy. This is more often seen in samples from old-growth forests than in the more open canopy situations frequently found in re-growth forests. In fact, it is often extreme enough that it can also be seen in the raw ring-width series. The sample tree appears to have reached canopy status sometime around 1785 , though the majority of the collection may have attained canopy status before 1750 (Figure 1).

Again, $B A I$ trend was determined from the regression of $B A I$ for the years after attaining canopy status $(\sim 1800$, Figure 2$)$. Three ring-width simulations were performed, based on radius length in 1800 of 4,6 or $10 \mathrm{~cm}$. If there was no change in slope of the BAI trend when the tree reached canopy size, then growth would have started in 1748 (when $B A I$ regression value $=0$ ) and reached a radius length of $6 \mathrm{~cm}$ by 1800 (Figure 1). The actual tree began growth at least as early as 1675 . Because simulations of $6 \mathrm{~cm}$ and $10 \mathrm{~cm}$ were both based on the same $B A I$ values, ring widths on the larger radius $(10 \mathrm{~cm})$ were necessarily smaller to begin with; however, by 2000 , they are essentially coincident with the 6-cm simulation (Figure 3). The third simulation began with a radius length in 1800 that was smaller $(4 \mathrm{~cm})$ than with the scenario of constant ring width for years that the tree was in the canopy. Because radius length was smaller, but $B A I$ was the same, simulated widths of the third simulation were larger in 1800. By about year 2000, values of this third simulation were also approaching a constant ring width. 


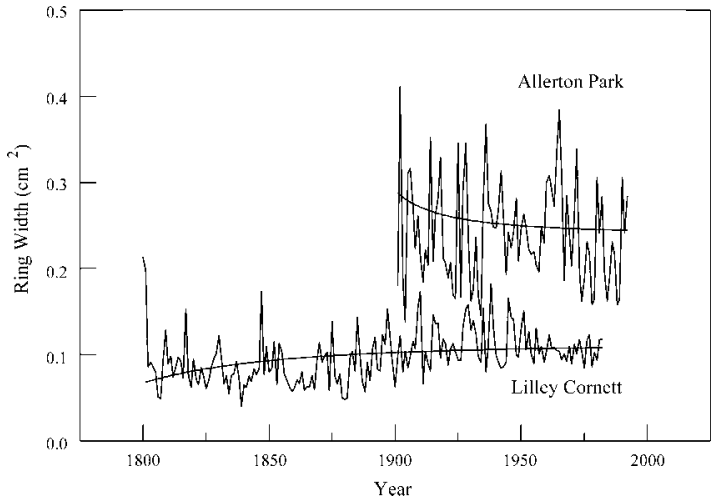

Figure 4. Ring-width simulation curves and actual ring widths for Allerton Park tree and Lilley Cornett tree for years since attaining canopy size (radius $>10 \mathrm{~cm}$ ).

\section{DISCUSSION}

The slope of the BAI trend of the Lilley Cornett collection is less before about 1750 than after. In contrast to the Allerton collection that was thought to be open-grown for the pre-canopy years, it would appear that the Lilley Cornett collection trees developed under an existing closed forest canopy. Attainment of canopy status resulted in a release as indicated by an increase in the slope of the $B A I$ trend. The constant ring-width trend of the canopy years was described as having resulted from constant $B A I$ slope both before and after reaching canopy status. Thus, it was simulated to have resulted in a smaller radius in 1800 $(6 \mathrm{~cm})$ than achieved by the actual tree $(10 \mathrm{~cm})$, and a trend of increasing ring width was simulated for the real-world situation scenario (Figure 3). The Allerton Park tree was simulated as having a greater radius length $(12 \mathrm{~cm})$ than in the real-world tree $(10 \mathrm{~cm})$ in 1900 , thereby resulting in a simulation of decreasing ring widths. In both cases, comparing actual widths with simulated curves, the simulated curves look as if they could have been curves fitted to the actual width data (Figure 4).

The Allerton Park white oak collection might be considered as having trees of fairly typical ages for a secondary or tertiary forest in the eastern deciduous forest. Ring-width trend of tree AWO1 continued to decrease for nearly 100 years after entering the canopy. At the time the trees were sampled, the ring-width curve of AWO-1 was just reaching a steady state. This may be fairly typical of canopy trees of many forests in the East. In other words, we should expect that increment core samples from most secondary forests in eastern North America show a decreasing ring-width trend for a hundred years or so after they reach canopy size.

The Lilley Cornett collection from eastern Kentucky contains trees that are comparatively older. The trend of increasing ring width illustrated for tree 103241 would be expected for trees that existed as suppressed understory trees before attaining canopy stature. Overstory trees from oldgrowth forests would be expected to show this pattern of increasing ring width for 100 or more years after having reached canopy status.

Tree-ring collections are more valuable if the stand represented by the collection does not have a history of stand disturbances. Determination of stability in the forest stand history can sometimes be aided by interpretation of ring-width trends. Simulations show a long-term trend of near-constant ring width, though 100-200 years may be required for ring width to adjust to a change in growth rate. The adjustment may be accomplished with either increasing or decreasing ring widths. As discussed, the adjustment in ring width may often result from a change in growth rate associated with a change in crown competition as the tree moves into the forest canopy.

\section{REFERENCES CITED}

Phipps, R. L., and J. C. Whiton

1988 Decline in long-term growth trends of white oak. Can. J. For. Res. 18:24-32.

Received 10 February 2004; accepted 15 July 2005. 